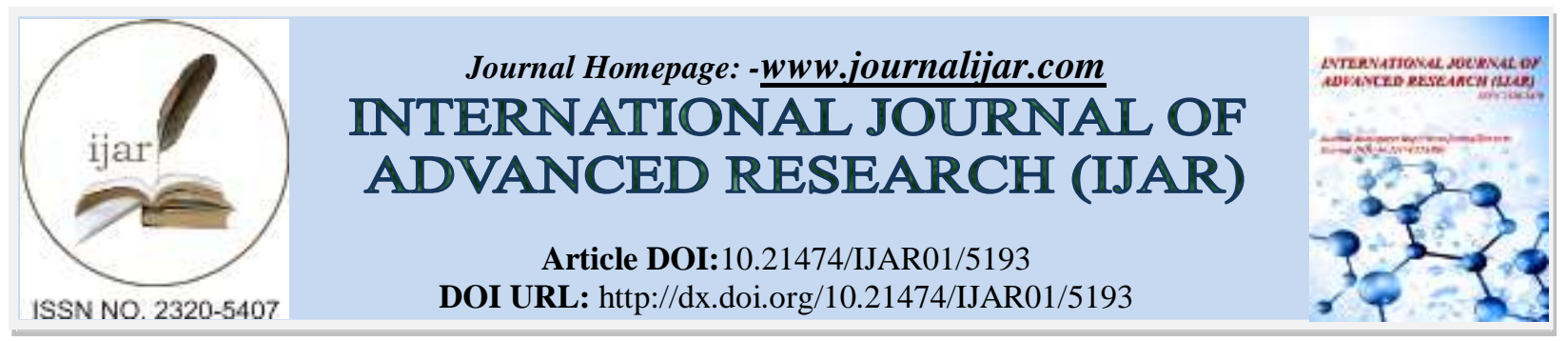

RESEARCH ARTICLE

\title{
EMPLOYEE SATISFACTION: A CASE STUDY OF INFORMATION AND COMMUNICATION TECHNOLOGY SECTOR IN BANGLADESH.
}

\begin{abstract}
Most. Moriom Khatun.
Manuscript Info

Manuscript History

Received: 16 June 2017

Final Accepted: 18 July 2017

Published: August 2017

Key words:-

Employee Satisfaction, Job Satisfaction,

ICT Sector in Bangladesh, Motivated

Employees.

Abstract

Employee satisfaction is the key point of successful business in a perfectly competitive market. However, such satisfaction of employee depends on several efforts and services such as salary, teamwork, company environment, etc. So, it is evident that perfect organizational practice and managerial decisions can make satisfied employees. In this regard, this paper analysis the ICT sectors in Bangladesh and figures out the satisfactory levels of the employees related to this sector. Fivelevel Likert item has been used for generating the questionnaires about employees' satisfaction of ICT sector in Bangladesh, which are divided into five different categorizes. The collected data has been analyzed and figured out that there is a significant relationship between employee satisfaction and managerial activities such as salary, reward, organization culture, promotion, etc. in the ICT sector of Bangladesh.
\end{abstract}

Copy Right, IJAR, 2017,. All rights reserved.

\section{Introduction:-}

Information and Communication Technology (ICT) is one of the leading sectors not only in Bangladesh but also all over the world. In Bangladesh, ICT industry is already seen as one of the top sectors in the country for graduate employment in terms of creating high quality and handsome salary jobs. According to Bangladesh Association of Software and Information Services (BASIS), the average monthly compensation for an ICT employee is approximately US\$ 200 per month. Comparing the size of the national population and the size of the national economy, it seems that the ICT industry in Bangladesh, especially the ICT exports, is still relatively small. Looking at the characteristics of the market, the global trend is offshoring, because of low employee cost. The growth of ICT services and products exported from Bangladesh is increasing over recent years. It can be concluded that the significance of the ICT sector for the Bangladeshi economy will grow in the near future. According to BASIS estimations within the next five years 10 percent of Bangladesh's total GDP will come from the software and IT services sector and over 150,000 Software and IT professionals will be working in the Bangladeshi IT industry. Since, ICT sector do not need any establishing manufacture cost, the employee salary is the leading cost in ICT sector budget. Hence, employee satisfaction plays the vital role to increase productivity in ICT sector.

\section{Literatures Survey:-}

Job satisfaction is defined as all the feelings that an individual has about his/her job. Researchers have attempted to identify the various components of job satisfaction, measure the relative importance of each component of job satisfaction and examine what effects these components have on workers' productivity. It has been suggested that human needs form a five-level hierarchy ranging from physiological needs, safety, belongingness and love, esteem 
to self-actualization [1]. Based on Maslow's theory, job satisfaction has been approached by some researchers from the perspective of need fulfillment $[1,2]$.

Kennerly investigated the relationship among administrative leadership behaviors, organizational characteristics, and faculty job satisfaction in baccalaureate nursing programs of private liberal art colleges [3]. The existence of organizational behaviors such as mutual trust, respect, certain warmth, and rapport between the dean/chair and the faculty member was a predictive factor in the development of nurse faculty job satisfaction. Billingsley and Cross studied 956 general and special educators in Virginia investigated commitment to teaching, intent to stay in teaching, and job satisfaction [4]. Findings of this study revealed greater leadership sup-port, work involvement, and lower levels of role conflict and stress-influenced job satisfaction for both groups studied

Herzberg et al. formulated the two-factor theory of job satisfaction and postulated that satisfaction and dissatisfaction were two separate and sometimes even unrelated phenomena [5]. Intrinsic factors named 'motivators' (that is, factors intrinsic to the nature and experience of doing work) were found to be job 'satisfiers' and included achievement, recognition, work itself and responsibility. Extrinsic factors which they named hygiene' factors were found to be job 'dissatisfies' and included company policy, administration, supervision, salary,

Spector has reviewed the most popular job satisfaction instruments and summarized the following facets of job satisfaction: appreciation, communication, co-workers, fringe benefits, job conditions, nature of the work itself, the nature of the organization itself, an organization's policies and procedures, pay, personal growth, promo promotion opportunities, recognition, security and supervision, Job satisfaction and its relating factors [6]. He also felt that, the above approach has become less popular with increasing emphasis on cognitive processes rather than on underlying needs so that the attitudinal perspective has become predominant in the study of job satisfaction. However, they did report that all of the factors of the Herzberg's theory were moderately related to job satisfaction. The increase in enrollment and the demands placed on faculty by the community, hospitals, and the college to produce a larger number of nursing graduates appears to be affecting morale and overall job satisfaction.

Hsiu Chin et al. findings were consistent with results of a study in Taiwan on Nurse Faculty job satisfaction and their perceptions of nursing deans' and directors' leadership styles [7]. Findings revealed that Taiwanese Nurse Faculty is moderately satisfied with their jobs and that they preferred that their dean use a transformational type of leadership. Ambrose et al. conducted a qualitative study to investigate faculty satisfaction and retention [8]. The study focused on the faculty of a private university over a period of 2 years. Findings suggested sources of satisfaction or dissatisfaction clustered into areas such as salaries, collegiality, mentoring, and the reappointment, promotion, and tenure process of departmental heads. Dainne Hagan presented the survey result on employer satisfaction with ICT graduates in Australia [9]. Tong et al. analyzed the impact of knowledge sharing on the relationship between organizational culture and job satisfaction of ICT industry in Hong Kong [10].

\section{Objective of The Study:-}

The present study is an attempt to examine the satisfaction at workplace from the perspectives of the ICT sector in Bangladesh. This research study also includes important findings regarding ICT services and employee satisfaction.

\section{Methodology:-}

\section{Survey Questionnaires}

The "Five Level Likert type Questionnaires" have been distributed to the randomly selected employees of the ICT sector in Bangladesh. Questionnaires solution has been designed for five several options, which are Strongly Disagree, Disagree, Neutral, Agree, and Strongly Agree. The total numbers of selected Questionnaires are twelve which have been categorized into five different segments. The Questionnaires with categories are listed below.

\section{Category 1: Salary, Reward, and Recognition}

1. The salary structure is fair in the comparison of other people working in the same field.

2. The promotion benefit provided by the company is standard.

3. Other benefits (Rent, Provident fund, Medical, etc.) provided by the company is satisfactory.

\section{Category 2: Organizational Culture}

4. Training facilities of the organization is satisfactory.

5. The work environment is safe and hazard free.

Category 3: Management Practices 
6. Management gives promotion opportunity fairly.

7. Management decides compensation and other benefits based on the performance.

\section{Category 4: Organizational Trust}

8. Organization does not interfere when you do your job.

9. Organization allows you to express opinions.

\section{Category 5: Team Work}

10. Supervisor and team members co-operate each other.

11. Team members take decisions together.

12. Supervisor promotes an atmosphere of teamwork.

\section{Sample Distribution:-}

The present study includes both quantitative and qualitative primary data collection through a field survey of the 85 (eighty five) sample respondents based on a structured questionnaire through the direct interview method. Respondents were selected purposively. Besides the interview method, other marketing research techniques like questionnaires, informal discussion, and participatory observation have also been used for primary data collection in this study. The empirical research work of the paper has been pursued to achieve the principal objective of the study. Table 1 to 3 exhibit the distribution of the sample respondents.

Gender: Here total respondent were 85 in number. Out of those 85 respondents, $74(87.1 \%)$ are male and the rest 11 $(12.9 \%)$ are female. As the research objective is to find out the antecedents of mid-level employees' satisfaction both male and female employees are equally important to be considered.

Table 1:-Percentage of male and female

\begin{tabular}{|l|l|l|l|}
\hline Gender & Frequency & Percent & Cumulative Percent \\
\hline Male & 74 & 87.1 & 87.1 \\
\hline Female & 11 & 12.9 & 100.0 \\
\hline Others & 0 & 0 & 0 \\
\hline Total & 85 & 100.0 & \\
\hline
\end{tabular}

Source: Survey Result

Age (in years):Here majority (57.6\%) of the respondents' fall under 30 years of age which is basically the young aged employees. Another 32.9\% of respondents fall under 30-39 years of age. So it can be concluded that around than $90 \%$ of the employees are relatively young and other $10 \%$ employees are in middle age.

Table 2:-Percentage of different age group people

\begin{tabular}{|l|l|l|l|}
\hline Age (years) & Frequency & Percent & Cumulative Percent \\
\hline $20-29$ & 49 & 57.64 & 49 \\
\hline $30-39$ & 28 & 32.94 & 77 \\
\hline $40-50$ & 6 & 7.06 & 83 \\
\hline $50+$ & 2 & 2.35 & 85 \\
\hline Total & 85 & 100 & \\
\hline
\end{tabular}

Source: Survey Result

Experience: Table 3 presents the $45.8 \%$ of the total respondents are working in the firm for 1-3 years which is a very significant percentage. While $29.4 \%$ are working for less than a year. Around other $15.29 \%$ are working here for more than 3 years. The percentage is quiet low which indicates that the firm has a very low employee retention rate.

Table 3:-Respondents experience

\begin{tabular}{|l|l|l|l|}
\hline Experiences (years) & Frequency & Percent & Cumulative Frequency \\
\hline Less than 1 year & 25 & 29.41 & 25 \\
\hline $1-3$ years & 39 & 45.88 & 64 \\
\hline - 6 years & 13 & 15.29 & 77 \\
\hline 6+ years & 8 & 09.41 & 85 \\
\hline Total & 85 & 100 & \\
\hline
\end{tabular}

Source: Survey Result 


\section{Research Problem:-}

The level of competition is very intense in the ICT industry of Bangladesh. Hence, each operator aims to ensure employee satisfaction by developing its competitive advantages through managerial activities, working environmental quality, team work, etc. For this reason, the companies of ICT sectors offer very handsome pay package with many other benefits and facilities to such kind of employees. But resourceful employees are scarce and retaining them is a challenge for the company if it cannot ensure proper job satisfaction.

\section{Research Question:-}

This study investigates the question: "Is there a significant relationship between managerial activities and employee satisfaction in the ICT sector of Bangladesh?"

\section{Research Proposition:-}

The study proposed that there is a significant relationship between managerial activities and employee satisfaction in the ICT sector of Bangladesh.

\section{ICT Sector in Bangladesh:-}

\section{Historical Perspective on the ICT Sector:-}

Bangladesh has about five decades of experience in using computers. In its early days the ICT sector in Bangladesh mainly focused on hardware operations. The first 'second generation', world mainframe, computer was installed in 1964 at Dhaka University. Soon after this several large banks and industrial concerns started using computers, mainly for accounting and payroll applications. Unfortunately the financial crisis that the country faced after its independence in 1971 hampered the expansion of computer use in the Bangladeshi corporate sector. In 1982 a computer center was established at the Bangladesh University of Engineering and Technology. This center, later renamed the Department of Computer Science \&Engineering, has played a pivotal role in Bangladeshi IT education since its inception. The Computer Center of the University of Dhaka was established in 1985, which boasts the history of hosting the first mainframe computer at the university and one of the first centers in Bangladesh to adopt digitization. With the possibility of using Bangla on computers the importance of computer use in offices and printing industries in Bangladesh rapidly grew. Soon after the introduction of the internet in Bangladesh, in 1995, the development of exportable software and multimedia systems commenced.

\section{Government Policy:-}

In June 1997 the Government of Bangladesh (GoB) officially recognized that ICT can make an important development impact by appointing a committee to look into barriers and opportunities to export software from Bangladesh. The Committee of Export of Software and Data Processing Services submitted a report to the government with 45 recommendations. The Committee, for instance, advised the government in the short term to support the ICT industry with tax holidays and specific exemptions, to provide the necessary authority to the BCC to function as the primary facilitator, to review computer science curricula, and to prepare over 1,000 new 'trainers' for national universities. For the medium term the committee recommended the creation of a 'Market Promotion Fund' to support installation of fiber optic cables and to coordinate setting up a communication hub in Bangladesh [11]. The GoB asked different concerned ministries to implement some of these recommendations [12].

In order to further develop the ICT sector and to realize the export potential of the sector, the GoB recently took several noteworthy initiatives:

- All Software and ICT Service companies, including those under foreign ownership, are exempt from income tax until 2015.

- Both a government sponsored long-term equity fund and short term working capital financing are offered to ICT companies.

- A special hi-technology and software technology park is being built by the government to facilitate the development of the entire infrastructure needed by companies that outsource activities to them. Furthermore the GoB has established the Bangladesh Hi-Tech Park Authority to operate the Hi-Tech Park.

\section{Overview of ICT Market in Bangladesh:-}

According to BASIS statistics from 2016 there currently are over 800 ICT companies registered in Bangladesh. The total industry turnover is estimated around 250 million USD. In 2016 BASIS carried out a survey among its member companies showing that over 75 percent of the member companies are involved with customized application development and maintenance. The specialization of the BASIS member companies is shown in Figure 1. 


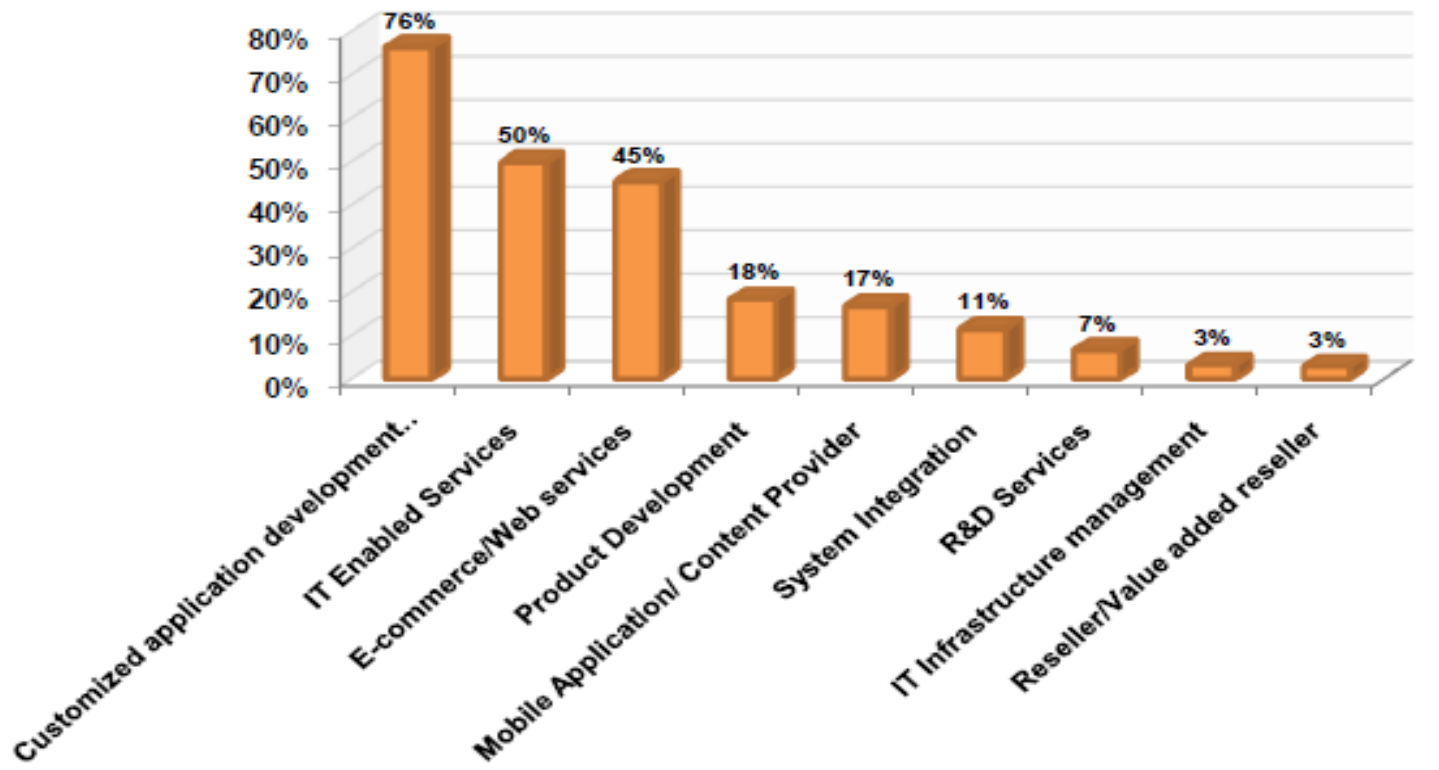

Figure 1:-Business specialization of BASIS member companies in 2016, source BASIS 2016.

Approximately 65 percent of BASIS' member companies have between 10 and 30 employees. It is estimated that not more than 20 companies have over 100 employees and just 5 companies in the Bangladeshi IT industry have over 200 employees. Based on these statistics it can be concluded that the market is dominated by Small and Medium Enterprises (SME). The ITC estimates that around 200 Bangladeshi ICT companies serve international markets by offering outsourcing services and project delivery models. The BASIS survey shows that out of the exporting member companies the revenue of around one third of these companies is fully export based. In terms of export destinations North America (Canada and the US) dominates, whereas European countries like the UK, Denmark, the Netherlands and Germany have emerged over the last few years to become major export destinations (see Figure 3 below). The DANIDA and the NTFII programs play an important role in this respect focused as they are on enhancing trade in the field of ICT between Bangladesh and Europe. The BASIS survey shows that of the exporting member companies in 2016 just 8.3 percent exports to India whereas 63.8 percent exports to the USA.

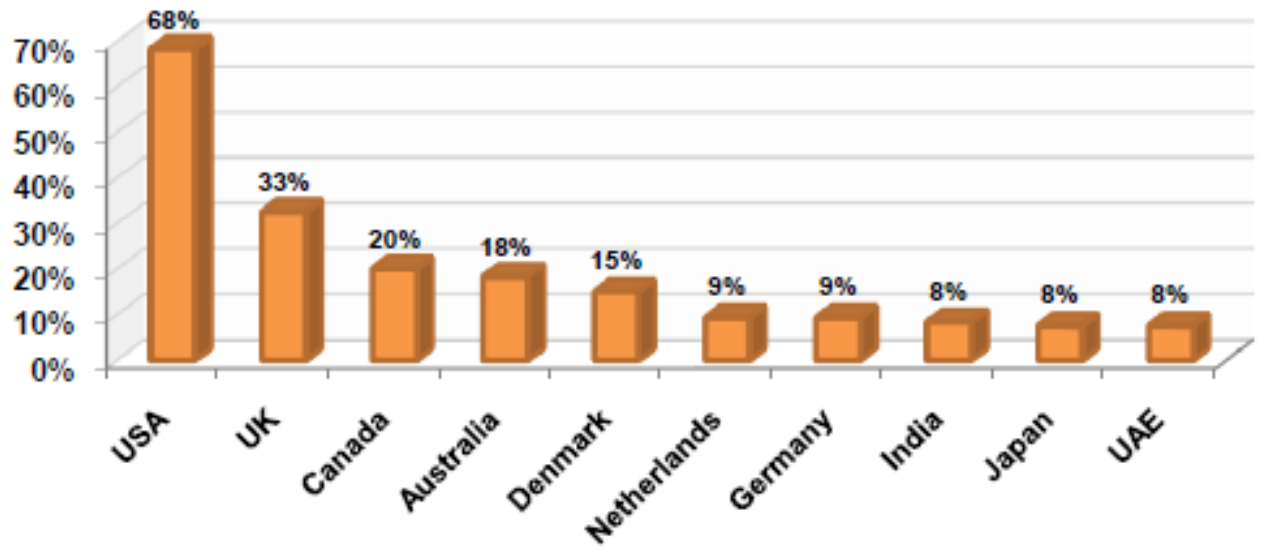

Figure 2:-Top export destinations BASIS member companies, source: BASIS 2016.

Apart from the 800 registered ICT companies Bangladesh has an active community of freelancers. According to the ICT Exporter Directory there are over 10,000 ICT freelancers active in Bangladesh in 2016, billing an export revenue over USD 7 million [13]. The Bangladeshi ICT freelance community bids for work on internet websites like oDesk, eLance and Guru. According to the KPMG freelance outsourcing jobs typically include editing, proof reading, translation, data entry, web research, virtual assistance, web design and software programming. 


\section{Analysis of ICT Market in Bangladesh:-}

An analysis to explore the possibilities of Bangladesh as an ICT off-shoring destination was conducted based on interviews with industry experts and practitioners from Bangladesh as well as the Netherlands. This analysis shows the Bangladeshi ICT sector as it is seen by current participants. The following section of the report will reflect on the offerings and strengths of the Bangladesh ICT sector as well as some risks and barriers. Overall the interviewees recognize that the Bangladesh ICT sector has the potential to become a global destination for offshoring. One of the biggest strengths of the Bangladeshi ICT sector, as mentioned in many interviews, is the young and educated workforce. In addition to the talented workforce, Bangladeshi ICT companies are very flexible in acquiring additional workforce if a project scales up. The cost advantages in Bangladesh are visible and reflected upon by many interviewees. As a developing market Bangladesh has a fair set of weaknesses. Most of them come from lack of skills, know-how and investment in the country. The main weakness of the Bangladeshi market remains infrastructure and power shortages. It is worth to mention that many of the bigger Bangladeshi ICT companies make use of fall back lines for internet and electricity. The internet connection in Bangladesh has become more reliable since the landline to India was laid next to the submarine cable from Singapore. The Bangladeshi ICT sector also suffers from poor international visibility and lack of brand name as a global offshoring destination. The Bangladeshi workforce has very well developed hard skills but is believed to be less developed on soft skills according to the interviewees. There is also a perceived gap between the industry needs and university qualification.

\section{Result Analysis and Findings:-}

Q: The salary structure is fair in the comparison of other people working in the same field.

This question was set to observe the perception of mid-level employees about the salary structure of the company and the industry. The result shows $25.9 \%$ employees were agreed directly with the statement while no one was strongly agreed. Here the concern should be about those $35.3 \%$ who are strongly disagree and $16.5 \%$ with disagreed on the above statement.

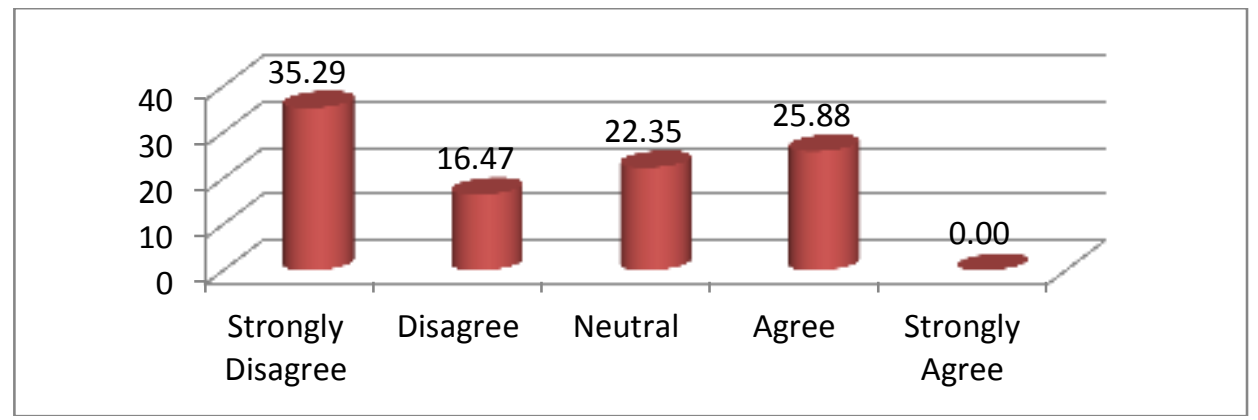

Figure 3:-Industry to company salary structure comparison

\section{Q: The benefits provided by the companies in ICT sectors are above the standard of Bangladesh.}

Now it's about the benefit company provides to its employees. About $25.88 \%$ employees believe that ICT sectors provide benefits which matches the standard in the comparison of other industry, when only $17.64 \%$ are strongly agreed. Again the concern is $17.64 \%$ strongly disagree and $15.29 \%$ disagree that is around $23.53 \%$ employees are neutral.

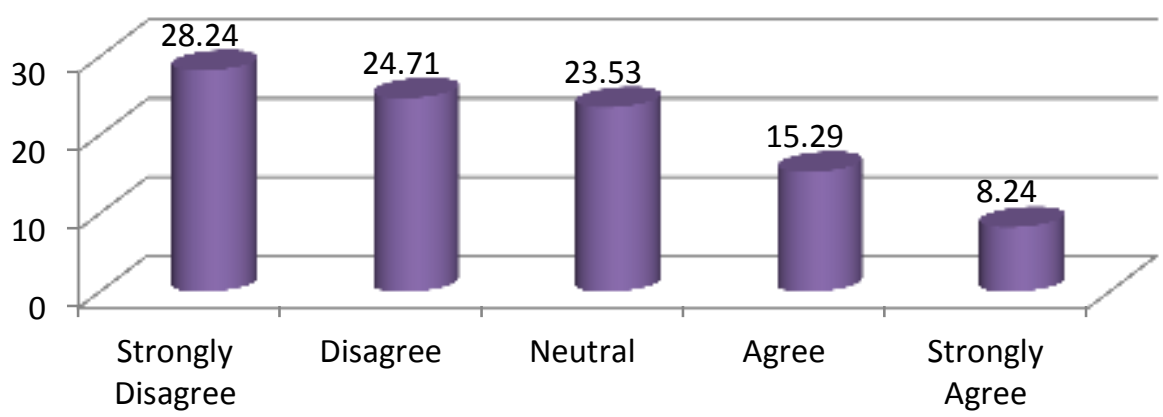

Figure 4:-Satisfactory level of available benefit 
Q: Other benefits (Rent, Provident fund, Medical insurance) provided by the company is satisfactory.

The picture shows only $15.29 \%$ respondents agree that the other job related benefits like rent, provident fund, medical insurance etc. are satisfactory. Only $8.23 \%$ strongly agree with the statement. But $24.70 \%$ of the respondents disagree with the matter and another $28.23 \%$ strongly disagree with the statement while $23.52 \%$ respondents are not willing to answer the question.

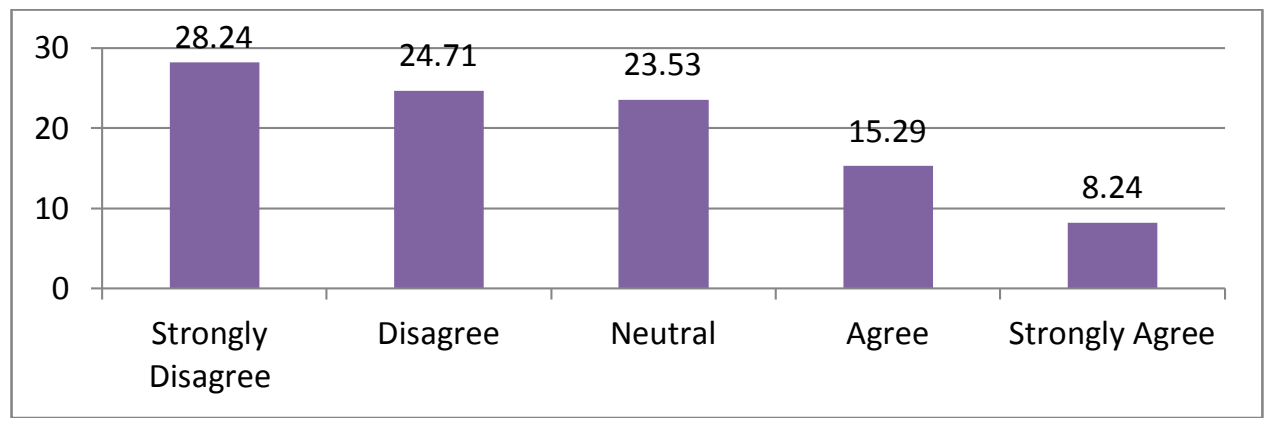

Figure 5:-Satisfactory Level regarding other benefits

Q: The work environment is safe and hazard free.

The picture describes how employees think about their environment in this company. As we see that $22.35 \%$ agree, $23.52 \%$ strongly agree, $17.64 \%$ neutral, while $22.35 \%$ disagree, $23.52 \%$ strongly disagree with the statement. That means work environment is closely related to the employees' job satisfaction in ICT sector of Bangladesh.

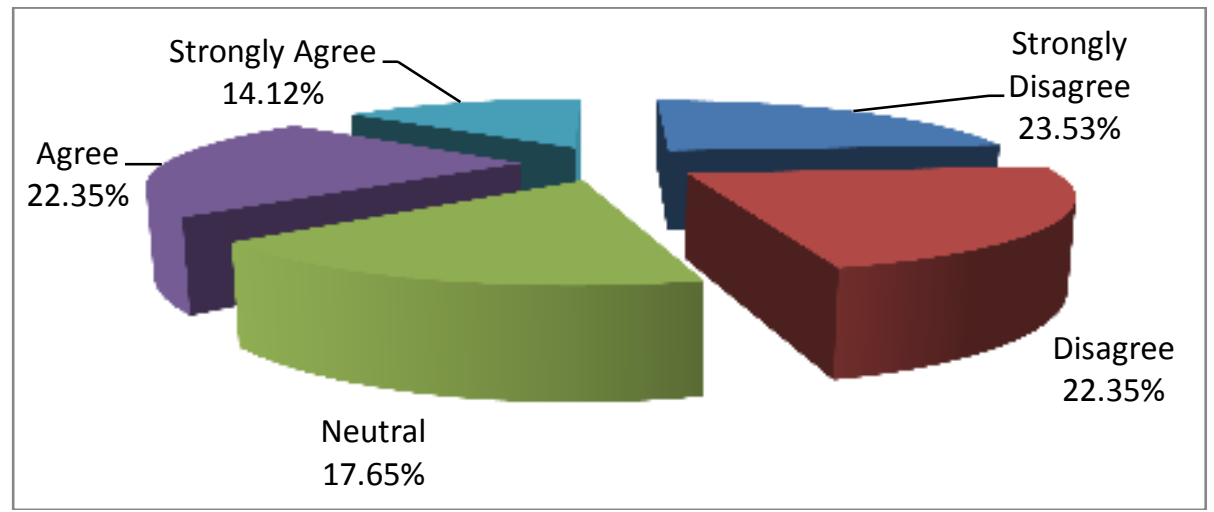

Figure 6:-Satisfactory Level in terms of work environment in organization

Q: Management decides compensation and other benefits based on the performance.

Out of 85 respondents each $4.7 \%$ are strongly disagreed and $10.58 \%$ disagreed, $34.11 \%$ agreed, $32.9 \%$ strongly agreed that they are satisfied about managerial decision of companies in ICT sector of Bangladesh. Though, rests $32.94 \%$ do not exactly sure about that the managerial decision about compensation and other benefits based on the performance.

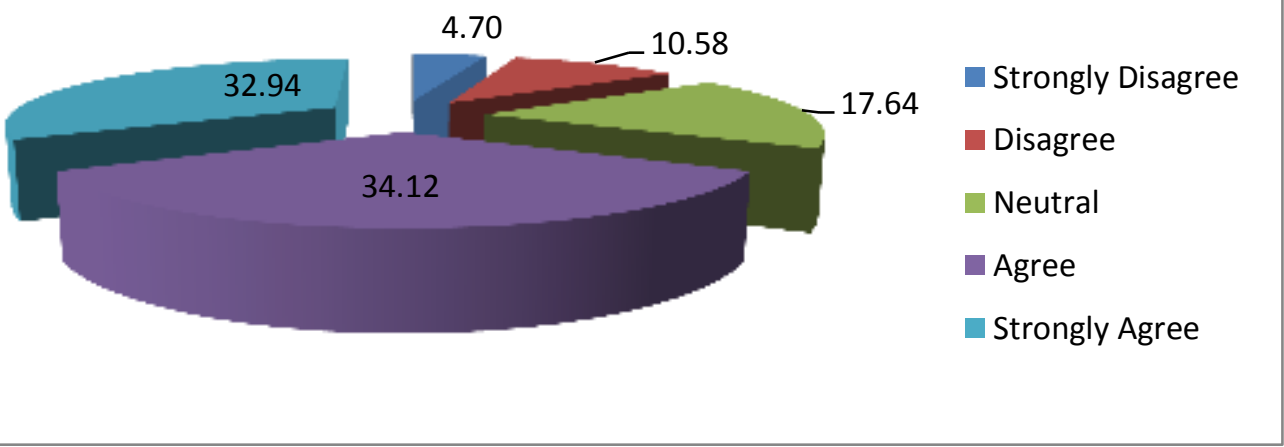

Figure 7:-Managerial decision about Compensation and other Benefits 


\section{Q: Organization allows you to express opinions}

The picture describes how employees noticed that their company allows to express opinions. As we see that $48.23 \%$ agree, $23.52 \%$ strongly agree, $11.76 \%$ neutral, while $9.41 \%$ disagree, $7.05 \%$ strongly disagree with the statement. That means the expression of opinions in organization is related to the employees' job satisfaction in ICT sector of Bangladesh.

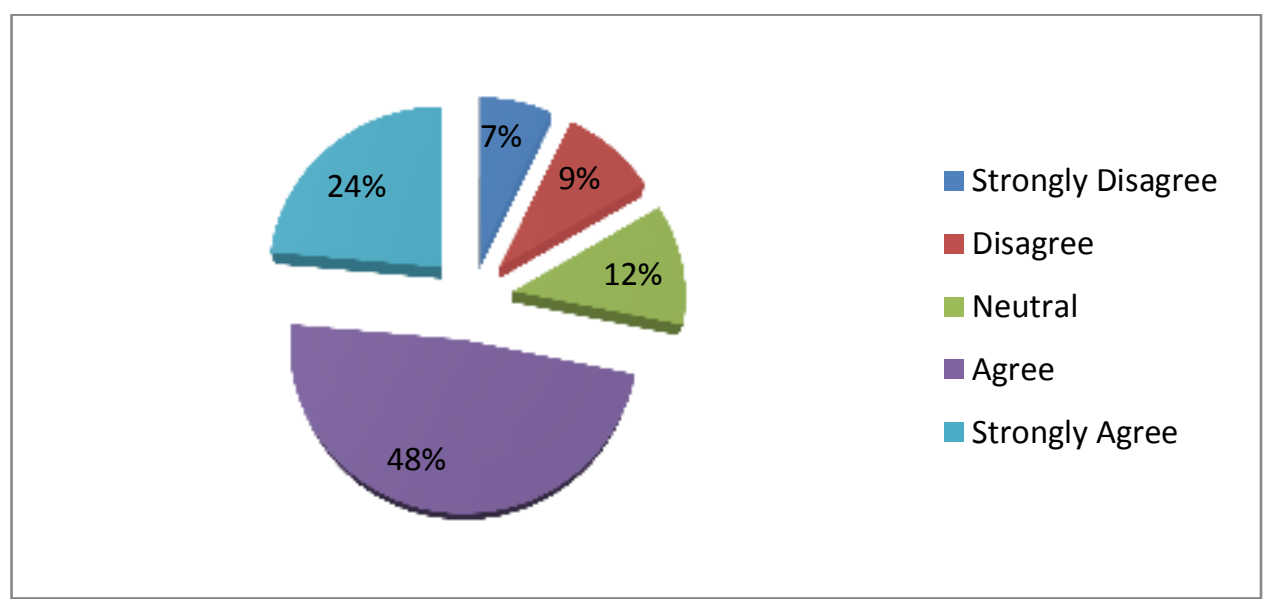

Figure 8:-Satisfaction level regarding their express opinion

\section{Conclusion and Recommendations:-}

This research examined the applicability and usefulness of measuring employees' job satisfaction in ICT sector of Bangladesh. The findings supported information in terms of its role in exploring specific perceptions and expectations of employees from the companies. The experiential results have not largely supported the hypotheses that were generated at the beginning of the research. It has been found that all the examined antecedents or dimensions namely Facilities, Organizational Culture, Management Practices, Teamwork etc. are not that much positively correlated with the selected segment Employees' Job Satisfaction of ICT sector in Bangladesh. However, an interesting observation got derived from the analysis which found out that antecedents such as Salary, Rewards, \& Recognition, Organizational Culture, Management Practices, Organizational Trust and Teamwork have major impact in terms of thinking about the job satisfaction. There has been repeated emphasis on the usefulness of this survey approach as a measure of employees' job satisfaction. This research work can highlight areas for specific action and address perceived actions that management can take.

Therefore in a nutshell, the present study had shown that despite of the existence of an overall moderate positive correlation between those parameters and mid-level employees' job satisfaction at the ICT sector companies, still when a further analysis was done as per individual company performance it has been depicted that out of the five dimensions of our parameter only four dimensions namely: Salary, Rewards \& Recognition, Management Practices, and Organizational Trust have a positive correlation with employees' job satisfaction. On the other hand, out of the five dimensions only two dimensions namely: Organizational Culture and Teamwork were found to have a very weak positive correlation with employee's current satisfaction level. The present research will aid the management of ICT sector in Bangladesh to enhance better understanding about the existing needs and expectations of the employees. Therefore, from the company's perspective they would come up with new ways to satisfy the existing employees for example improving Job satisfaction (which is the dependent variable in this study).

\section{References:-}

1. Maslow, Abraham H. "The instinctoid nature of basic needs." Journal of Personality 22, no. 3 (1954): 326-347.

2. Kuhlen, Raymond G. "Needs, perceived need satisfaction opportunities and satisfaction with occupation." Journal of Applied Psychology 47, no. 1 (1963): 56.

3. Kennerly, Susan M. "Leadership behavior and organizational characteristics: Implications for faculty satisfaction." Journal of Nursing Education 28, no. 5 (1989): 198-202.

4. Billingsley, Bonnie S., and Lawrence H. Cross. "Predictors of commitment, job satisfaction, and intent to stay in teaching: A comparison of general and special educators." The journal of special education 25, no. 4 (1992): 453-471. 
5. Herzberg, G., and L. L. Howe. "The Lyman bands of molecular hydrogen." Canadian Journal of Physics 37, no. 5 (1959): 636-659.

6. Spector, Paul E. Job satisfaction: Application, assessment, causes, and consequences. Vol. 3. Sage publications, 1997.

7. Chen, Hsiu Chin, Susan L. Beck, and Linda K. Amos. "Leadership styles and nursing faculty job satisfaction in Taiwan." Journal of Nursing Scholarship 37, no. 4 (2005): 374-380.

8. Ambrose, Susan, Therese Huston, and Marie Norman. "A qualitative method for assessing faculty satisfaction." Research in Higher Education 46, no. 7 (2005): 803-830.

9. Hagan, Dianne. "Employer satisfaction with ICT graduates." In Proceedings of the Sixth Australasian Conference on Computing Education-Volume 30, pp. 119-123. Australian Computer Society, Inc., 2004.

10. Tong, Canon, WalderIpWahTak, and Anthony Wong. "The impact of knowledge sharing on the relationship between organizational culture and job satisfaction: The perception of information communication and technology (ICT) practitioners in Hong Kong." International Journal of Human Resource Studies 3, no. 1 (2013): 9.

11. MoC 1997, Ministry of Commerce, Letter of Transmittal (14 September 1997), Sustainable Development Networking Programme,

12. BCC 2014, Bangladesh Computer Council, website: <http://www.bcc.net.bd/>, last visited: 15 June, 2017.

13. NTFII (2012), ITC Exporter Directory, Website: < http://www.intracen.org/itc/projects/ntf-ii/bangladesh/> Last Visit: 23 August 2017 